\title{
Finite-Element-Based Multiple Normal Loading-Unloading of an Elastic-Plastic Spherical Stick Contact
}

\author{
Biplab Chatterjee and Prasanta Sahoo \\ Department of Mechanical Engineering, Jadavpur University, Kolkata 700032, India \\ Correspondence should be addressed to Prasanta Sahoo; psjume@gmail.com
}

Received 30 October 2012; Accepted 19 November 2012

Academic Editors: J. Antunes and F. Findik

Copyright (c) 2013 B. Chatterjee and P. Sahoo. This is an open access article distributed under the Creative Commons Attribution License, which permits unrestricted use, distribution, and reproduction in any medium, provided the original work is properly cited.

\begin{abstract}
The repeated normal elastic plastic contact problem of a deformable sphere against a rigid flat under full stick contact condition is investigated with a commercial finite element software ANSYS. Emphasis is placed on the effect of strain hardening and hardening model with the maximum interference of load ranging from elastic to fully plastic, which has not yet been reported. Different values of tangent modulus coupled with isotropic and kinematic hardening models are considered to study their influence on contact parameters. Up to ten normal loading-unloading cycles are applied with a maximum interference of 200 times the interference required to initiate yielding. Results for the variation of mean contact pressure, contact load, residual interference, and contact area with the increasing number of loading unloading cycles at high hardening parameter as well as for low tangent modulus with two different hardening models are presented. Results are compared with available finite element simulations and in situ results reported in the literature. It is found that small variation of tangent modulus results in same shakedown behavior and similar interfacial parameters in repeated loading-unloading with both the hardening rules. However at high tangent modulus, the strain hardening and hardening rules have strong influence on contact parameters.
\end{abstract}

\section{Introduction}

Multiple repeated normal loading unloading is common in engineering applications. Several researchers have identified the use of repeated normal loading unloading in various fields of engineering applications such as contact resistance in MEMS micro switches $[1,2]$, head-disk interaction in magnetic storage systems [3], ultrasonic interfacial stiffness measurement [4], stamping mechanism, and in rolling element bearings, gears, cams, and so forth. Earlier the problems of multiple loading-unloading were solved assuming a specific pressure distribution. The contact region related to the analysis of Kapoor et al. [5], Williams et al. [6] did not exceed greatly the elastic limit; hence they assumed Hertzian [7] contact. Merwin and Johnson [8], Kulkarni et al. [9], Bhargava et al. $[10,11]$ used Hertzian or modified Herzian pressure distribution even for elastic plastic contacts. In most engineering applications, the contact deformation occurred in elastic plastic as well as in plastic region. The arbitrary selection of pressure distribution where the plasticity effects are dominant eventually would provide inaccurate solution. Beyond the Hertzian assumption of nonadhesive frictionless contact within elastic limit, commercial finite element software is best suited to calculate accurately the contact parameters like contact load, contact area, and pressure in the elastic plastic and plastic region [12]. The contact analysis of the rough surfaces involves the study of single asperity contact. Kogut and Etsion [13] first provided an accurate result of elastic plastic loading of a hemisphere against a rigid flat using commercial finite element software ANSYS. They used finite element analysis under frictionless condition for a wide range of material elastic properties and sphere size to present generalized empirical relations for contact area, contact load, and mean contact pressure as a function of dimensionless interference. Their investigations in elastic, elastic plastic, and plastic regions also include the effect of plastic properties of the material. Kogut and Etsion inferred that the variation of tangent modulus, plastic property of the 
material, up to 10 percent of modulus of elasticity yielded in maximum 20 percent difference of contact parameters. Etsion et al. [14] extended their investigation for unloading under perfect slip contact condition with tangent modulus of 2 percent of modulus of elasticity. They used bilinear isotropic hardening. Jackson et al. [15] studied the effect of elastic properties of material on residual deformation and concentrated on the residual stresses of the sphere under perfect slip contact condition. Kadin et al. [16] offered a multiple loading-unloading model with isotropic hardening using $0.02 E$ tangent modulus under perfect slip contact condition. They found that the incipient interference required for the secondary plastic flow in the peripheral zone increases with the increase in tangent modulus. Kral et al. [17] performed repeated normal indentation of a half space by a rigid sphere under perfect slip contact condition using isotropic hardening. It was shown that the effect of plastic properties like strain hardening is more pronounced rather than the elastic properties of the material on the contact parameters during loading unloading in the elastic plastic and plastic region. They used strain-hardening exponent (n) up to 0.5. Sahoo et al. [18] studied the effect of strain hardening for elastic plastic loading of a deformable sphere against a rigid flat for frictionless and non-adhesive contact by varying the hardening parameter $(H)$ up to 0.5 . Variation of hardening parameter up to 0.5 enabled them to study the effect of tangent modulus as high as 33 percent of modulus of elasticity. They inferred that the increase in strain hardening increases the resistance to deformation of a material and the material becomes capable of carrying higher amount of load in a smaller contact area. However Chatterjee and Sahoo [19] observed that the contact loads after first and second loading were same under perfect slip contact condition for non-hardening material as well as material with hardening parameter of 0.5 .

The aforementioned reviews are related to frictionless contact condition. Friction is useful in many engineering applications such as brakes, clutches, bolts, nuts, driving wheels on automobiles, and so forth whereas unproductive friction takes place in engines, gears, cams, bearings, and seals [20]. Brizmer et al. [21] found that the pressure distribution and the stress field near the contact surfaces at low contact loads are different for perfect slip and full stick contact condition. Chatterjee and Sahoo [22] studied the effect of elastic properties of material for an elastic plastic loading of a deformable sphere against a rigid flat under full stick contact condition. Zait et al. [23] performed the unloading of an elastic plastic spherical contact under full stick contact condition. They found a substantial variation in load area curve during unloading under full stick contact condition compared to that under perfect slip contact condition. Zait et al. [24] expanded the previous single complete unloading under full stick contact condition to include multiple normal loading unloading. They used bilinear kinematic hardening with tangent modulus as 2 percent of modulus of elasticity. They concluded identical shakedown behavior for both isotropic and kinematic hardening. Chatterjee and Sahoo [25] studied the effect of strain hardening on the elastic plastic contact loading of a deformable sphere against a rigid flat under full stick contact condition with two different hardening rules. It was observed that the material with isotropic hardening has higher amount of load carrying capacity than that of kinematic hardening particularly for higher strain hardening. Johnson [26] mentioned that the surface tractions and nonlinear material properties are the factors to influence the reversibility of cyclic normal loading in spherical contact problems. Thus under a specific contact condition (slip or stick), the plastic properties of the material and the hardening rule have a particular importance in multiple normal loadingunloading. Though under perfect slip (frictionless) contact condition the effect of strain hardening on loading unloading of a deformable sphere against a rigid flat is available in literature, the effect of plastic properties and hardening model for multiple normal loading-unloading for a deformable spherical contact under full stick contact condition is still missing.

The present investigation therefore aims at studying the effect of strain hardening and hardening models on contact parameters during multiple normal loading-unloading of a deformable sphere against a rigid flat under full stick contact condition using commercial finite element software ANSYS.

\section{Theoretical Background}

Figure 1 shows the contact of a deformable sphere and a rigid flat. The dashed line presents the original contour of the sphere, having a radius of $R$, and the rigid flat before the deformation. The solid line shows the loading phase with the interference $(\omega)$, corresponding to the contact radius $(a)$, and the contact load $(P)$.

Multiple loading unloading consists repeated normal loading and complete unloading. During loading phase, the interference $(\omega)$ is increased up to the specified maximum dimensionless interference, $\omega_{\max }^{*}$. During unloading, the interference $(\omega)$ is gradually reduced. At the end of the unloading, under zero contact load and contact area, the sphere has a residual interference $\left(\omega_{\text {res }}\right)$. Therefore the original un-deformed spherical geometry is not fully recovered. The original profile, the deformed shape after loading phase and the sphere profile at the end of unloading in single loading unloading are represented in Figure 2. Stick contact condition is applied at the interface of the deformed sphere and the rigid flat. The stick contact condition prevents the contact point of the deformed sphere with the rigid flat from the relative displacement in the radial direction but it allows the axial detachment of the sphere surface from the rigid flat during unloading.

In the present study, multiple normal loading-unloading is simulated considering both the isotropic and kinematic hardening models. Figure 3 describes the difference between isotropic hardening and kinematic hardening by describing the development of the yield surface with progressive yielding. In isotropic or work hardening, the yield surface is uniformly spread out from the center while in kinematic hardening the yield surface translates in stress space with constant size. The variation of different contact parameters is considered with the increase in loading or unloading cycles 


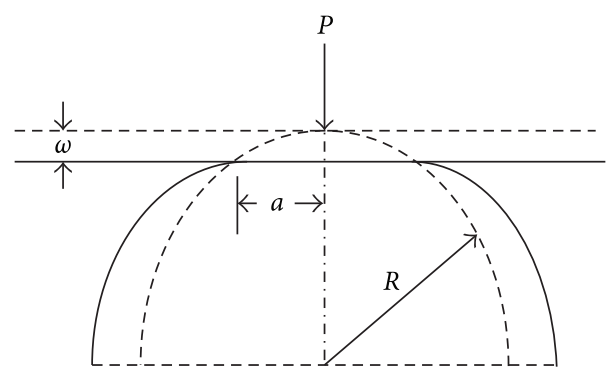

FIGURE 1: A deformable sphere pressed by a rigid flat.

in the present study. The contact loads, contact area, mean contact pressure in repeated normal loading are normalized by their corresponding values after first loading. Similarly residual interference after repeated unloading is normalized by its value after first unloading. The contact parameters and the interferences in some cases are normalized with their critical values in a manner as described in Chatterjee and Sahoo [25]. The following empirical relations are used to evaluate the critical interference $\left(\omega_{c}\right)$, which initiates the yield inception at first loading and the corresponding critical load $\left(P_{c}\right)$ and critical contact area $\left(A_{c}\right)$ under full stick condition:

$$
\begin{aligned}
& \omega_{c}=\left(C_{v} \frac{\pi\left(1-v^{2}\right)}{2}\left(\frac{Y}{E}\right)\right)^{2} \\
& \times R\left(6.82 v-7.83\left(v^{2}+0.0586\right)\right), \\
& P_{c}= \frac{\pi^{3} Y}{6} C_{v}^{3}\left(R\left(1-v^{2}\right)\left(\frac{Y}{E}\right)\right)^{2} \\
& \times\left(8.88 v-10.13\left(v^{2}+0.089\right)\right) \\
& A_{c}=\pi \omega_{c} R .
\end{aligned}
$$

Here, $C_{v}$ is a parameter that depends on Poisson's ratio as $C_{v}=1.234+1.256 v$. The parameters $Y, E$, and $v$ are the virgin yield stress, the Young modulus, and Poisson's ratio of the sphere material, respectively, and $R$ is the radius of the sphere. The sphere size used for this analysis is $R=1 \mu \mathrm{m}$. The material properties used here are Young's Modulus $(E)$ $=70 \mathrm{GPa}$, Poisson's Ratio $(v)=0.3$, and Yield stress $(Y)=$ $100 \mathrm{MPa}$. For full stick contact condition, infinite friction condition is adopted.

\section{Finite Element Model}

A commercial finite element package ANSYS 11.0 is used in the present study in order to get the accurate solution of a complicated subject like multiple loading-unloading under full stick contact condition. The sphere is represented by a quarter of a circle, due to its axisymmetry. A line models the rigid flat. The elements as shown in Figure 4 consists the mesh of maximum 18653 number of plane183 finite elements. Plane 183 is six-node triangular axisymmetric element. The mesh density at the bottom of the sphere is coarsest one and is made gradually finer towards the

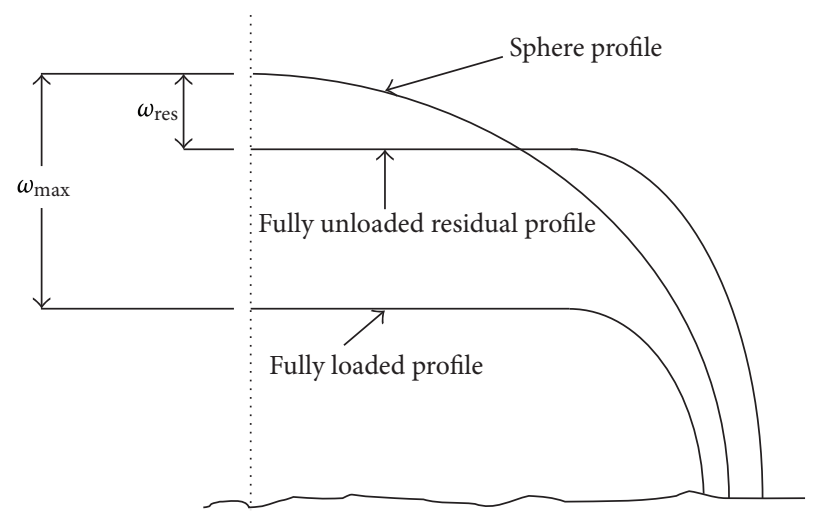

FIGURE 2: Three different profiles of the sphere.

sphere summit. The finest mesh density near the contact region simultaneously allows the sphere's curvature to be captured and accurately simulated during deformation with a reduction in computation time. Window 2 of Figure 4 presents the enlarged view of the finest mesh density at sphere summit. The detail description and boundary condition of FE model can be found in [25].

\section{Results and Discussion}

Engineering stress-strain curves are used within elastic limit. The dimension of the specimen changes substantially in the region of plastic deformation. The increment of strain in conjunction with true stress can be termed as strain hardening. Strain hardening causes an increase in strength and hardness of the metal. Strain hardening is expressed in terms of tangent modulus $\left(E_{t}\right)$, which is the slope of the stress-strain curve. Below the proportional limit the tangent modulus is the same as the Young's modulus $(E)$. Above the proportional limit the tangent modulus varies with the strain. The tangent modulus is useful in describing the behavior of materials that have been stressed beyond the elastic region. In elastic perfectly plastic cases, the tangent modulus becomes zero. Very few material exhibit elastic perfectly plastic behaviors, generally all the materials follow the multilinear behavior with some tangent modulus. This multi-linear behavior can be assumed as bilinear behavior for analysis purpose in elastic-plastic cases. In this analysis a bilinear material property, as shown in Figure 5, is used for the deformable sphere. Shankar and Mayuram [27] mentioned that the tangent modulus for the most practical materials is less than $0.05 E$, whereas Kadin et al. [16] found the tangent modulus for most practical materials below $0.02 E$. However both the authors used tangent modulus up to $0.1 E$ for analytical purpose. On the other hand, Ovcharenko et al. [28] used stainless steel specimen with tangent modulus of $0.26 \mathrm{E}$ (Figure 6(b)) in their in situ investigation). It is also available in literature that structural steel, aluminum alloys have significant amount of strain hardening.

Figure 6(a) represents the load interference hysteretic loop during ten repeated loading unloading. The maximum dimensionless interference for loading is $\omega^{*}=100$, with 


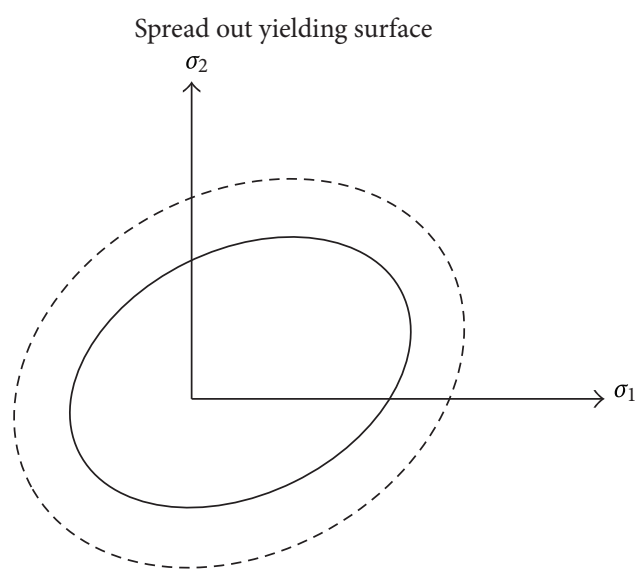

(a)

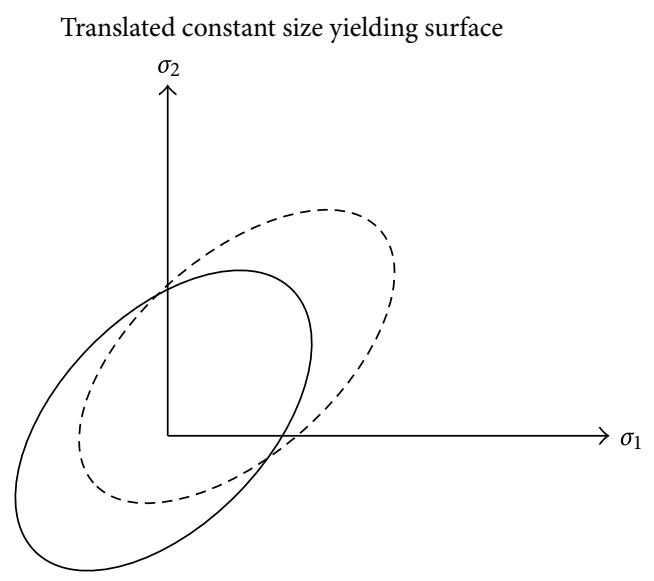

(b)

FIGURE 3: (a) Isotropic and (b) kinematic hardening models for two-dimensional stress field.

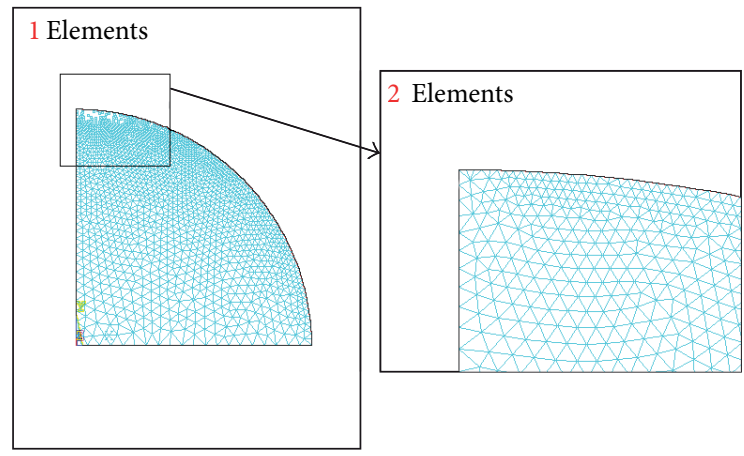

FIGURE 4: Finite element mesh of a sphere generated by ANSYS.

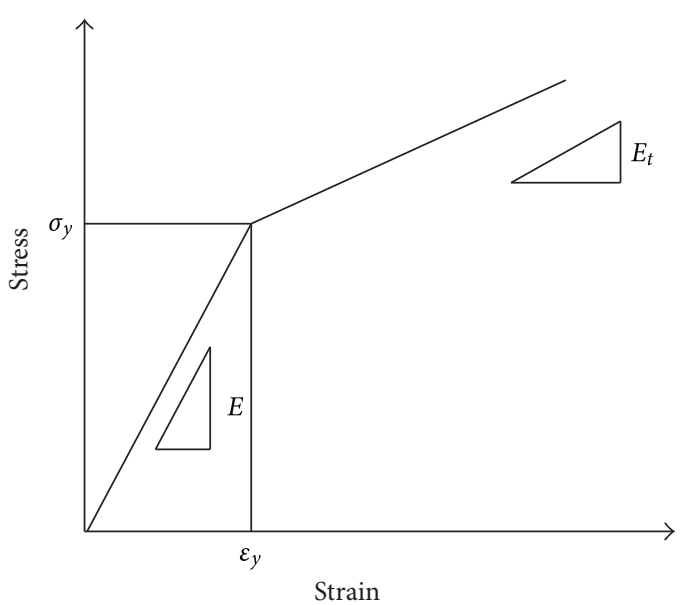

FIGURE 5: Stress-strain diagram for a material with bilinear properties.

tangent modulus, $E_{t}=0.025 E$ using kinematic hardening. This simulation was performed to validate the present results with Zait et al. [24]. Zait et al. furnished the results (Figure 4) with maximum dimensionless interference of 60 using kinematic hardening. They have shown that with small tangent modulus the materials result in elastic shakedown even under the influence of kinematic hardening. The agreement between the present simulation and the results of Zait et al. [24] is appreciably good. Figures 6(b) and 6(c) are the details of Figure 6(a). Figure 6(b) shows the decrease of maximum contact load with the increase in loading cycles for multiple loading unloading for the same dimensionless interference of loading. Figure 6(c) presents the increase of residual interferences with the increase in unloading cycles during ten loading unloading cycles. Zait et al. [24] also observed the decrease of maximum contact load and increase of dimensionless interference during multiple loading unloading.

4.1. Interfacial Parameters with Low Tangent Modulus. In the first part of present analysis, materials are chosen as elastic perfectly plastic material and the materials with tangent modulus of $0.025 E, 0.05 E$, and $0.09 E$ for studying the effect of strain hardening with both isotropic and kinematic hardening rule. Figure 7 (a) presents the normalized contact load, $P / P_{0}$ during ten loading-unloading cycles with bilinear isotropic hardening. $P_{0}$ is the contact load after the completion of first loading. The maximum loading was performed up to a dimensionless interference of $\omega_{\max }^{*}=100$. It is found that the contact load decreases with each loading-unloading cycle. Chatterjee and Sahoo [19] found identical contact load in second loading (Figures 9(a) and 9(b)) with bilinear isotropic hardening under perfect slip contact condition. So this decrease in contact load is due to the contact conditions, which was also inferred by Zait et al. [24]. The decrease of contact load with increase in loading cycles depends on strain hardening. The decrease in contact load is less with increase in tangent modulus. The decrease of contact loads after ten loading-unloading cycles are 9.5, 7.73, 7, and 5.1 percent for materials with tangent modulus of $0.0 E, 0.025 E, 0.05 E$, and $0.09 E$, respectively.

Figure 7(b) represents the normalized contact load, $P / P_{o}$ during ten loading unloading in case of bilinear kinematic hardening with maximum loading up to the dimensionless 


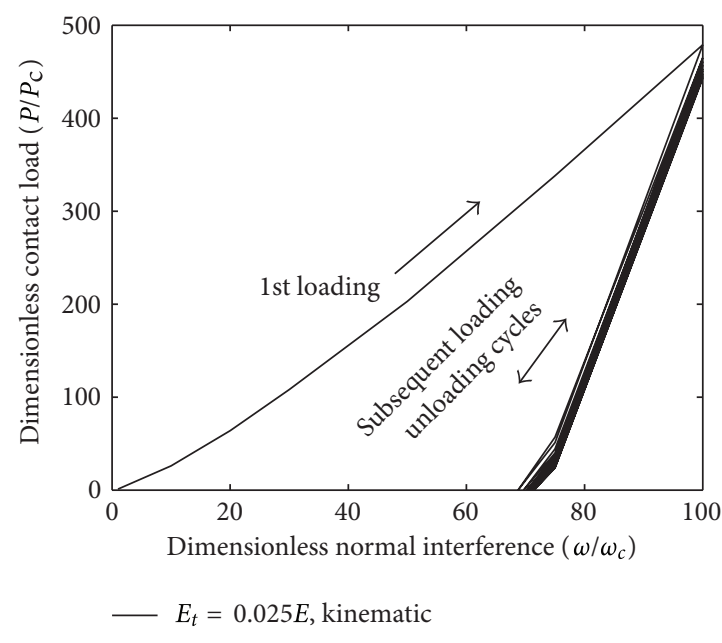

(a)

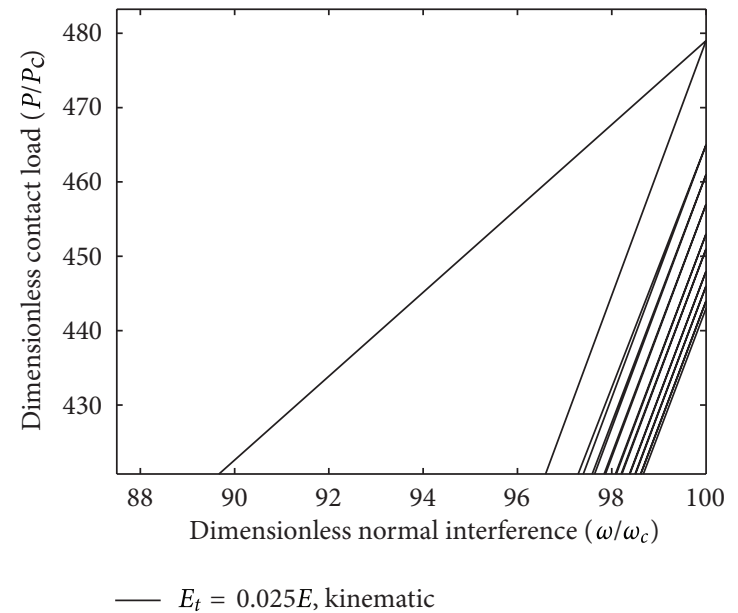

(b)

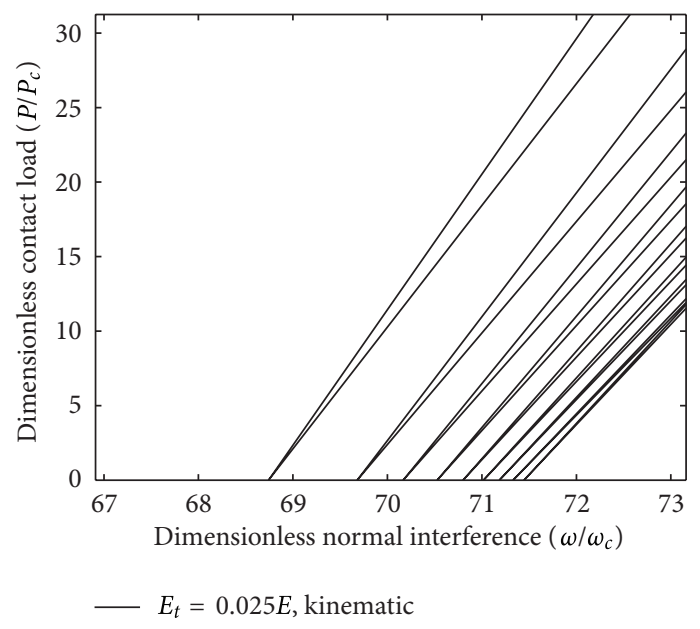

(c)

Figure 6: (a) The load-interference hysteretic loop during ten loading-unloading cycles following maximum loading to a dimensionless interference of $\omega^{*}=100$ (b) Increase of residual interferences and decrease of contact load. (c) Increase of residual interferences.

interference of $\omega_{\max }^{*}=100$. The decrement trend of contact load is same for both the hardening rule. The decrease of contact loads after ten loading-unloading cycles are 9.5, 7.55, 6.5 and 2.8 percent for materials with tangent modulus of $0.0 E, 0.025 E, 0.05 E$ and $0.09 E$ respectively. It is seen from the results of both the hardening rules that the decrease of contact load is less with kinematic hardening than that of isotropic hardening. Elastic perfectly plastic materials are insensitive to the hardening rule; however the contact load using isotropic and kinematic hardening with the increase in loading cycle has significant variation for higher tangent modulus.

Figure 8(a) is the plot of normalized residual displacement, $\omega_{\text {res }}^{*} / \omega_{\max }^{*}$, during ten loading unloading cycles with bilinear isotropic hardening. The residual displacement or interferences are found after complete unloading. The contact load and area becomes zero after complete unloading. The residual interferences are normalized by the maximum dimensionless interference of loading. The maximum dimensionless loading interference is $\omega_{\max }^{*}=100$. It can be seen from the plot that the normalized residual interference during ten loading-unloading cycles is dependent on tangent modulus. The normalized residual displacement decreases with the increase of tangent modulus. The normalized residual displacement in case of elastic perfectly plastic material is 3.2, 6.4, and 11.52 percent higher after ten loading-unloading when compared with the materials having tangent modulus of $0.025 E, 0.05 E$, and $0.09 E$, respectively. Kadin et al. [16] also observed that higher hardening results in lower residual strain.

Figure 8(b) shows the normalized residual displacement, $\omega_{\text {res }}^{*} / \omega_{\max }^{*}$, as a function of loading cycles with bilinear kinematic hardening. It is revealed from the figure that after ten loading unloading, the normalized residual displacement of elastic perfectly plastic material is 3.61, 8.26, and 20.57 percent higher than that with the materials having tangent modulus of $0.025 E, 0.05 E$, and $0.09 E$, respectively. Comparing the results with isotropic and kinematic hardening, it is observed that using kinematic hardening yields less residual 


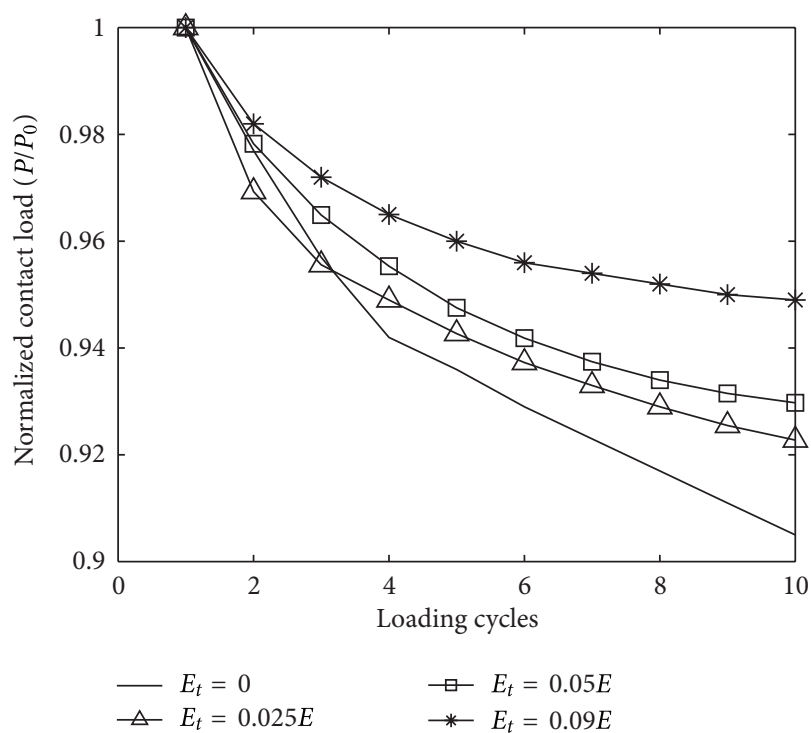

(a)

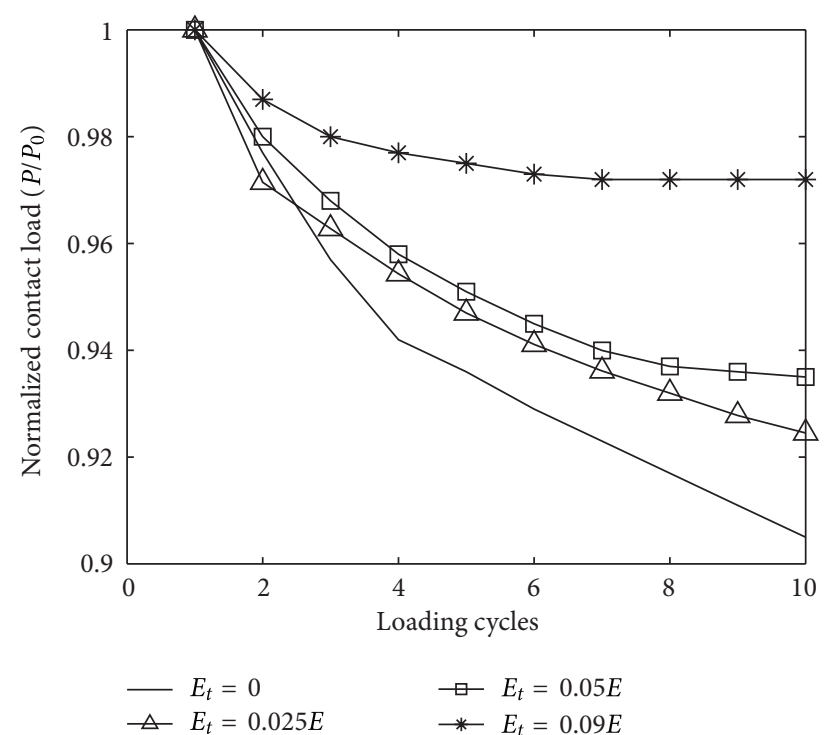

(b)

Figure 7: Normalized contact load, $P / P_{0}$, as a function of loading cycles with (a) bilinear isotropic hardening, (b) bilinear kinematic hardening.

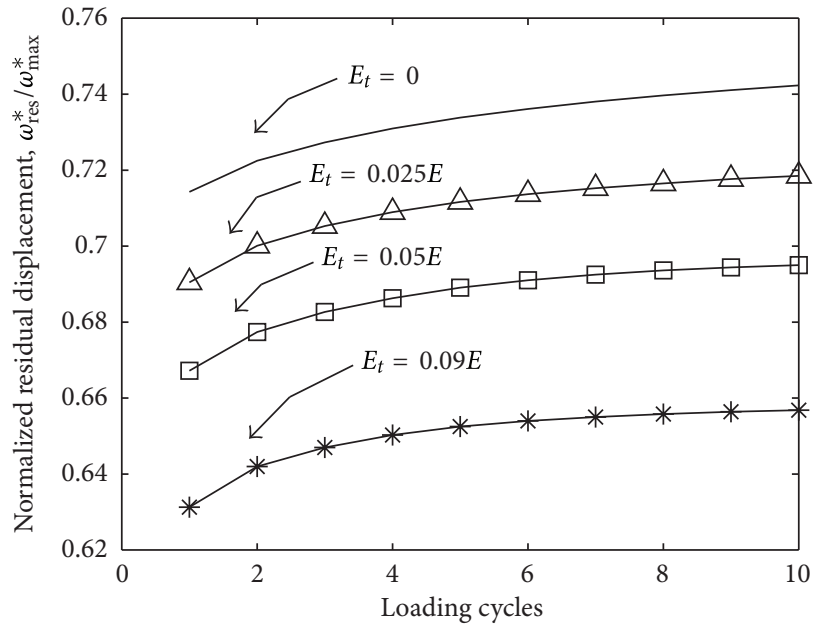

(a)

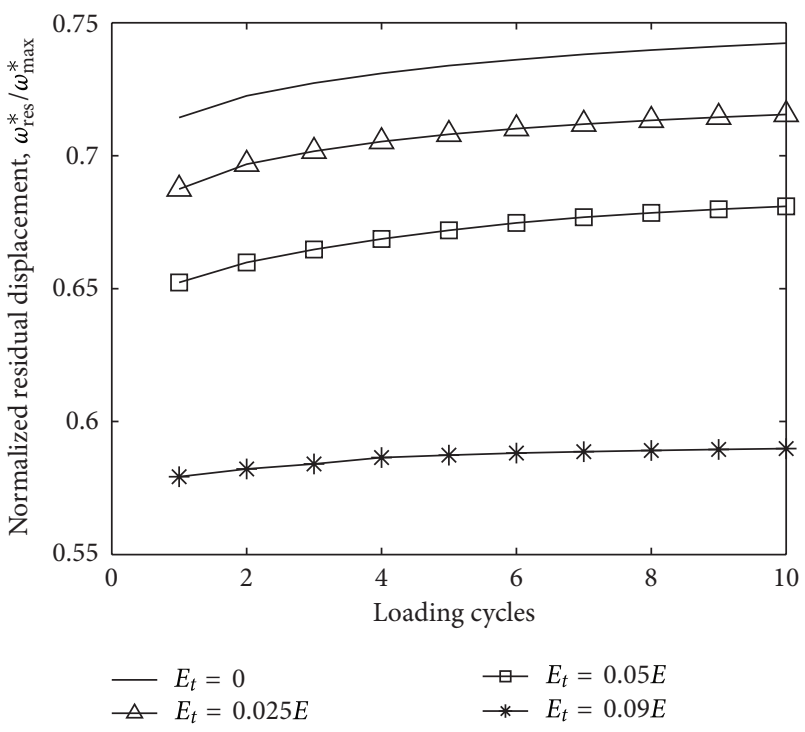

(b)

FIgURE 8: Normalized residual interference, $\omega_{\text {res }}^{*} / \omega_{\max }^{*}$, as a function of loading cycles with (a) bilinear isotropic hardening, (b) bilinear kinematic hardening.

displacement than that with isotropic hardening. This is more pronounced for the materials with high tangent modulus. Zolotarevskiy et al. [29] studied the elastic plastic spherical contact under cyclic tangential loading in presliding with $2 \%$ hardening and found the tangential displacement at the completion of the first cycle is less in the case of kinematic hardening compared to that in the isotropic hardening. The agreement between Zolotarevskiy et al. and present results is excellent.
Figure 9 shows the increment of residual interference of $\omega_{\text {res }}^{*}$ with respect to $\omega_{\text {res } 0}^{*}$ (residual interference after first unloading) during ten unloading. We have studied the effect of hardening type also. It can be seen from the figure that the increase of residual interference after tenth unloading with respect to the residual interference after first unloading ranges from 4 to 4.5 percent irrespective of hardening type and tangent modulus except the simulation with tangent modulus of $0.09 \mathrm{E}$ using kinematic hardening. The simulation 


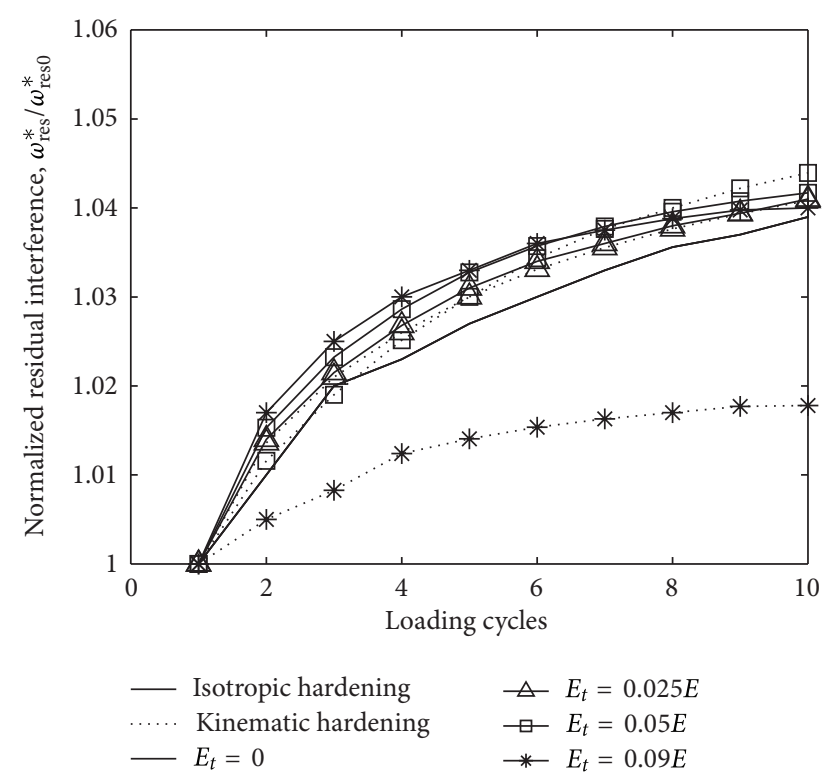

FIGURE 9: Normalized residual interference, $\omega_{\text {resx }}^{*} / \omega_{\text {res } 0}^{*}$, as a function of loading cycles for maximum loading, $\omega_{\max }^{*}=100$.

of material with tangent modulus of $0.09 \mathrm{E}$ and kinematic hardening resulted in 1.8 percent increase of residual interference after ten unloading with respect to residual interference after first unloading. The study of contact load and residual interferences during ten loading unloading with tangent modulus up to $0.09 \mathrm{E}$ and two different hardening type clearly indicates that the interfacial parameters depend predominantly on the extent of strain hardening and hardening rule with the increase in tangent modulus.

4.2. Interfacial Parameters with High Tangent Modulus. It is necessary to investigate the effect of strain hardening and hardening rule on interfacial parameters with higher tangent modulus to understand the response of the materials with significant amount of strain hardening such as stainless steel, structural steel and aluminum alloys in repeated loading unloading. In our forth-coming simulations, the tangent modulus $\left(E_{t}\right)$ is varied according to a hardening parameter $(H)$. The hardening parameter is defined as $H=E_{t} /\left(E-E_{t}\right)$. We have considered four different values of $H$, covering wide range of tangent modulus to depict the effect of strain hardening in single asperity multiple loading unloading contact analysis with other material properties being constant. The values of $H$ used in this analysis are within range $0 \leq H \leq 0.5$ as most of the practical materials falls in this range [30]. The value of $H$ equals to zero indicates elastic perfectly plastic material behavior, which is an idealized material behavior. The hardening parameters used for this analysis and their corresponding $E_{t}$ values are shown in Table 1 .

4.2.1. Mean Contact Pressure Distribution. Figure 10(a) is the plot of dimensionless mean contact pressure $(p / Y)$ as a function of ten loading cycles. The maximum dimensionless interference for loading is $\omega_{\max }^{*}=50\left(P_{\max }^{*}=196\right.$ for
TABLE 1: Different $H$ and $E_{t}$ values used for the study of strain hardening effect.

\begin{tabular}{lcc}
\hline$H$ & $E_{t}$ in $\% E$ & $E_{t}(\mathrm{GPa})$ \\
\hline 0 & 0.0 & 0.0 \\
0.1 & 9.0 & 6.3 \\
0.3 & 23.0 & 16.1 \\
0.5 & 33.0 & 23.1 \\
\hline
\end{tabular}

elastic perfectly plastic material after first loading). Brizmer et al. [21] used $2 \%$ linear hardening and found dimensionless mean contact pressure around 2.7 for normalized contact load of 200. Our simulation resulted dimensionless mean contact pressure 2.5 after first loading for dimensionless interference of 50 . Therefore the present results correlate well with the findings of Brizmer et al. [21]. The mean contact pressures increase with the increase of tangent modulus for both the isotropic and kinematic hardening rule. For the tangent modulus ranging from $0.09 E$ to $0.33 E$, the increase of mean contact pressures with isotropic hardening are in the range of 46.56 to 118 percent than that elastic perfectly plastic material after ten loading cycles whereas the increase of mean contact pressures with kinematic hardening ranges from 42 to 113 percent for the same range of tangent modulus after ten loading cycles. This indicates that the effect of tangent modulus or strain hardening on the mean contact pressure is significantly more pronounced than the hardening rule.

Figure 10(b) shows the dimensionless mean contact pressure during ten loading cycles for the maximum dimensionless interference of $\omega_{\max }^{*}=100$ It is clear from the figure that the mean contact pressure intensified with the increase in dimensionless interference of loading. Mean contact pressure using isotropic hardening increased from 15.98 to 34.5 percent after ten loading cycles for the four indicated tangent modulus in the figure with the increase of dimensionless interference of loading from 50 to 100 . It is also observed from the figure that a marginal deviation of mean contact pressure is resulted with kinematic hardening. As already mentioned earlier that the elastic perfectly plastic material is insensitive to the hardening rule, the evolution of mean contact pressure depends predominantly on the strain hardening characteristics and the intensity of loading rather than the hardening rule.

Figure 10(c) represents the evolution of dimensionless mean contact pressure at the end of each seven loading cycles for the maximum dimensionless interference of $\omega_{\max }^{*}=200$. The evolution of mean contact pressure clearly indicates the same qualitative trend of Figures 10 (a) and 10(b). It can be seen from the figure that the evolution of mean contact pressure with isotropic hardening is higher than that with kinematic hardening. The dimensionless mean contact pressures with isotropic hardening are 6.4, 8.9, and 8.8 percent higher after first loading than that with kinematic hardening for the materials having tangent modulus of $0.09 \mathrm{E}$, $0.23 E$, and $0.33 E$, respectively.

Kral et al. [17] simulated repeated indentation of a half space by a rigid sphere with isotropic hardening. They used three strain hardening exponent as $0,0.3$, and 0.5 and 


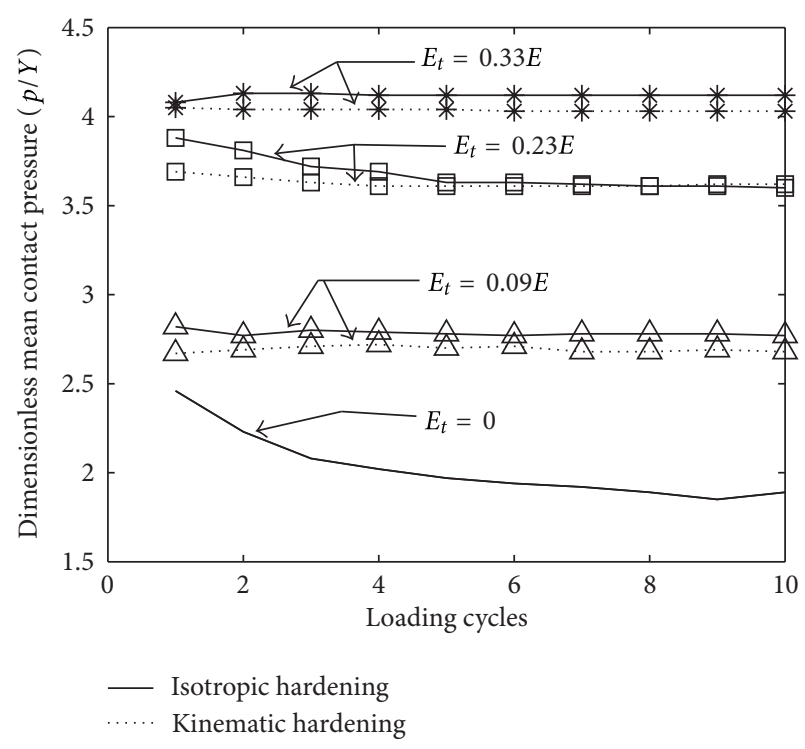

(a)

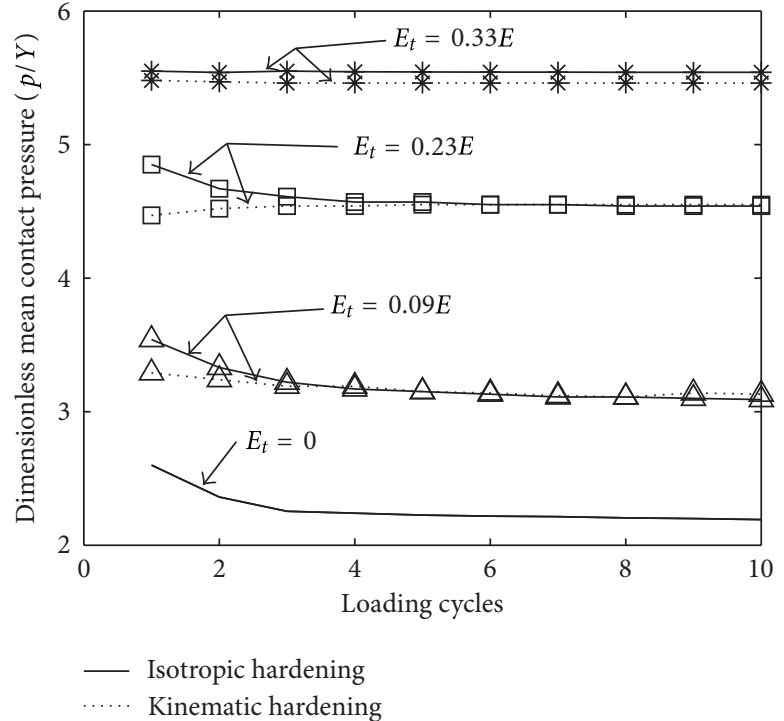

(b)

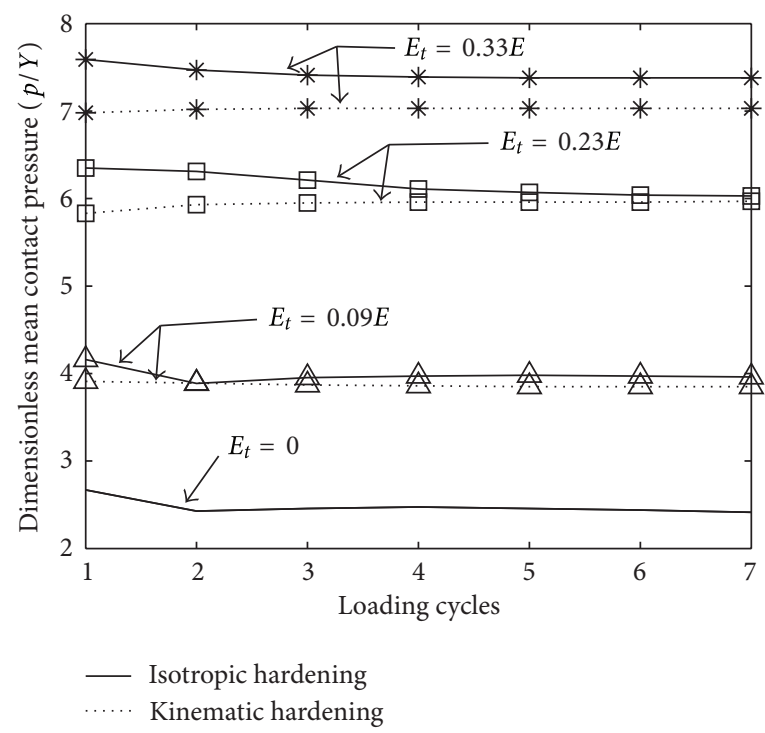

(c)

Figure 10: Dimensionless contact pressure, $p / Y$, as a function of loading cycles for maximum loading, (a) $\omega_{\max }^{*}=50,(\mathrm{~b}) \omega_{\max }^{*}=100,(\mathrm{c})$ $\omega_{\max }^{*}=200$.

indentation load up to 300 times the load necessary for initial yield. Kral et al. inferred that the distribution of contact pressure over the contact area increases with increasing load and strain hardening characteristics (Figures 4(b) and 8). There is no scope of comparison as we have simulated with a deformable sphere against a rigid flat but the qualitative natures of present results (Figures $10(\mathrm{a})-10(\mathrm{c})$ ) are in good agreement with the results of Kral et al.

The deviation of mean contact pressure with the increase of loading cycles for varying tangent modulus in case of isotropic and kinematic hardening is shown in Figure 11. The maximum dimensionless interference of loading is $\omega_{\max }^{*}=$ $100, p_{0}$ represents the mean contact pressure after first loading. It is found from the figure that the variation of mean contact pressure after every cyclic loading depends on the tangent modulus or the strain hardening characteristics and hardening type. It can also be seen from the figure that the mean contact pressure decreases with the increasing loading cycle for the materials with isotropic hardening irrespective of the extent of tangent modulus though the decrease is not so prominent with kinematic hardening. Kral et al. [17] also mentioned that the maximum contact pressure is lower in second load half cycle in case of an indentation of a half space by a rigid sphere with isotropic hardening. The decrease of mean contact pressures with isotropic hardening after second loading compared to first loading are 9.3, 5.8, 3.8, and 0.2 percent for the materials with tangent modulus of 0 , $0.09 E, 0.23 E$, and $0.33 E$, respectively. The decrement of mean 

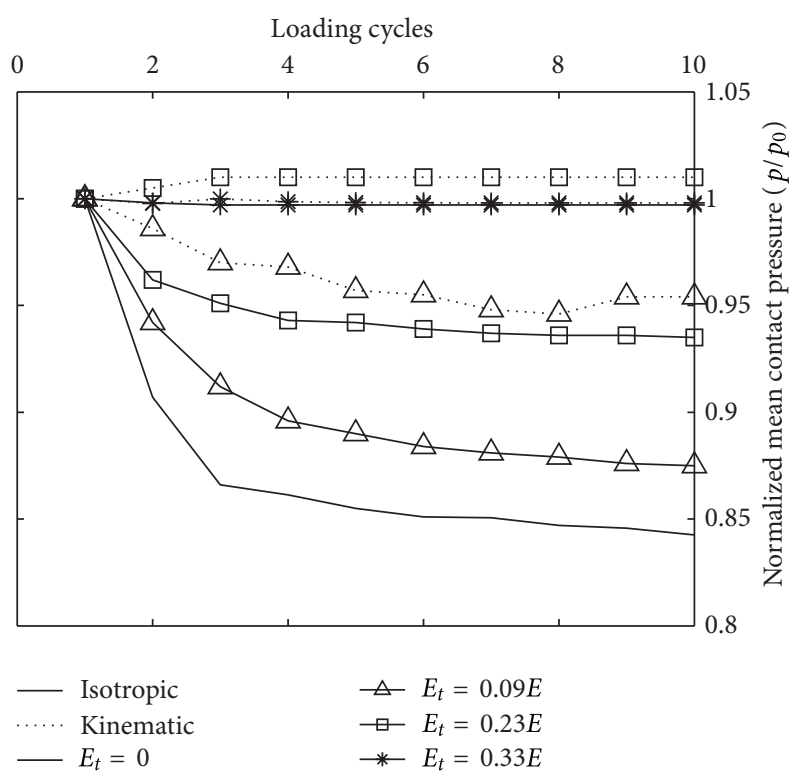

FIgURE 11: Normalized contact pressure, $p / p_{0}$, as a function of loading cycles for maximum loading, $\omega_{\max }^{*}=100$.

contact pressure with isotropic hardening is consistent with increasing loading cycles, after tenth loading the decreases are $15.74,12.5,6.5$, and 0.3 percent compared to the mean contact pressure after first loading for the materials with tangent modulus of same order as mentioned for second loading. It is therefore imperative that the maximum decrement rate of mean contact pressure is occurred after second loading cycle and the decreases in subsequent cycles are insignificant. Kral et al. also observed the same pressure profile distribution after second load half cycle. However the variations of mean contact pressure with the increasing loading cycles are not pronounced in case of kinematic hardening.

4.2.2. Dimensionless Load with Loading Cycles. The variation of normalized contact load up to ten loading cycles for both isotropic and kinematic hardening rule is plotted in Figure $12(\mathrm{a}) . P_{0}$ is the contact load after first loading and the maximum dimensionless loading for the simulation of repeated loading unloading is $\omega_{\max }^{*}=100$. The contact load decreases with the increase in loading cycle and the rate of decrease is the function of hardening rule and tangent modulus. The decrease of contact load with the increase of loading cycle is more pronounced in isotropic hardening than the kinematic hardening. The material with less tangent modulus produced more variation in contact load with the increase in each load cycle.

Figure 12(b) shows the variation of normalized contact load up to seven cyclic loading for the maximum loading of dimensionless interference $\omega_{\max }^{*}=200$. Figures 12(a) and 12(b) demonstrate that the variation of contact load with each loading cycle significantly depends on the extent of maximum loading interference. The decrease of contact load with maximum dimensionless loading interference of 200 after seventh cyclic loading is $2 \%$ more even after the tenth cyclic loading with maximum dimensionless loading interference of 100 for the elastic perfectly plastic material. However the materials with high tangent modulus $\left(E_{t}=\right.$ $0.33 E$ ) and kinematic hardening produced no variation of contact load with the increase of loading cycle.

4.2.3. Residual Displacements. Figure 13(a) shows normalized residual interference, $\omega_{\text {res }}^{*} / \omega_{\text {max }}^{*}$, after each unloading during ten loading unloading cycles for maximum dimensionless interference of loading, $\omega_{\max }^{*}=100\left(P_{\max }^{*}=459\right.$ for elastic perfectly plastic material). It reveals from the figure that the residual displacement depends predominantly on the tangent modulus and hardening rule. The residual displacement for the materials with the largest tangent modulus $\left(E_{t}=0.33 E\right)$ using isotropic hardening is about $61 \%$ that of the elastic perfectly plastic material after first unloading. Kral et al. [17] found half residual displacement for material with strain hardening exponent 0.5 compared with the elastic perfectly plastic material after first unloading under perfect slip contact condition. They simulated with maximum dimensionless load, $P_{\max }^{*}=300$ and inferred that above $P_{\max }^{*}=50$, the contact load increases significantly with the increase of strain hardening for the same indentation depth. Chatterjee and Sahoo [25] reported the same qualitative results while studying the effect of strain hardening during the loading of a deformable sphere against a rigid flat under full stick contact condition. The residual displacement with isotropic hardening is significantly higher than that of with kinematic hardening for higher tangent modulus. After first unloading the residual displacements with isotropic hardening are 9,52 , and 86 percent higher than the residual displacement with kinematic hardening for the materials with tangent modulus of $0.09 E, 0.23 E$, and $0.33 E$, respectively.

Figure 13(b) shows the normalized residual displacement after each unloading for seven loading unloading cycles. The maximum dimensionless interference of loading for this simulation is $\omega_{\max }^{*}=200$. The normalized residual displacements after first unloading increased up to $12 \%$ for the increase of dimensionless interference of loading from 100 to 200 . Hardening rule and the extent of loading has a significant effect on residual displacement.

Figure 14(a) presents the increment of residual interference with the increase of unloading cycles compared with the residual interference after first unloading. $\omega_{\text {res } 0}^{*}$ is the residual interference after first unloading. It reveals from the figure that the increases in residual interferences with isotropic hardening are significantly more than that with kinematic hardening. The figure also demonstrates that the increment of residual interference with the increase in unloading cycles depends on tangent modulus. Higher tangent modulus yields slightly less increment of residual interference with the increase in unloading cycles.

Figure 14(b) shows the normalized residual interference during seven loading unloading cycles for the maximum dimensionless interferences of loading $\omega_{\max }^{*}=200$. Figures 14(a) and 14(b) indicates that higher dimensionless interference of loading produces marginally less increment 


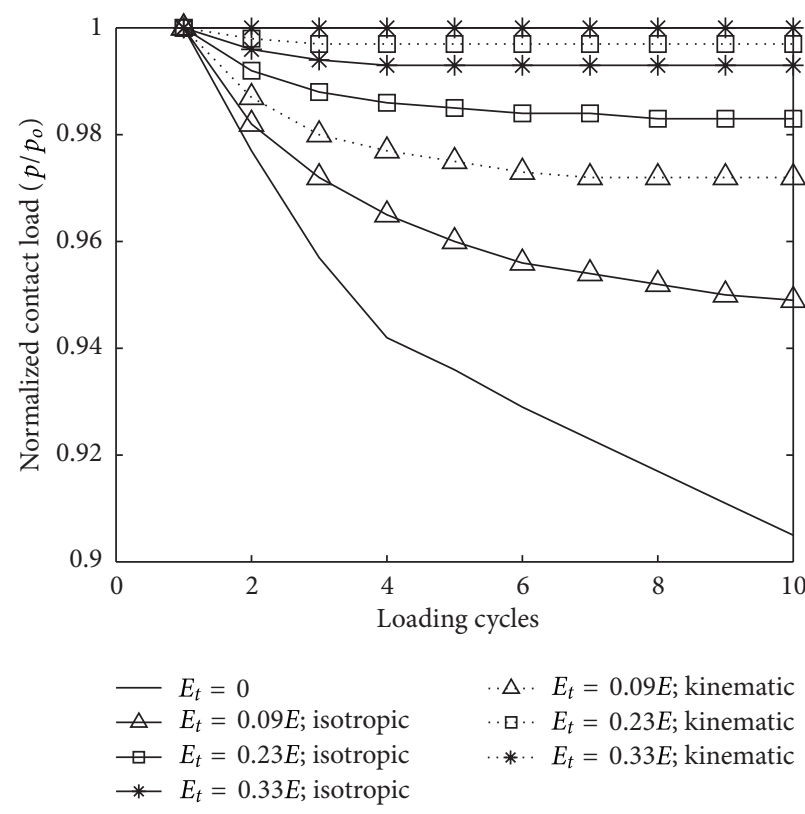

(a)

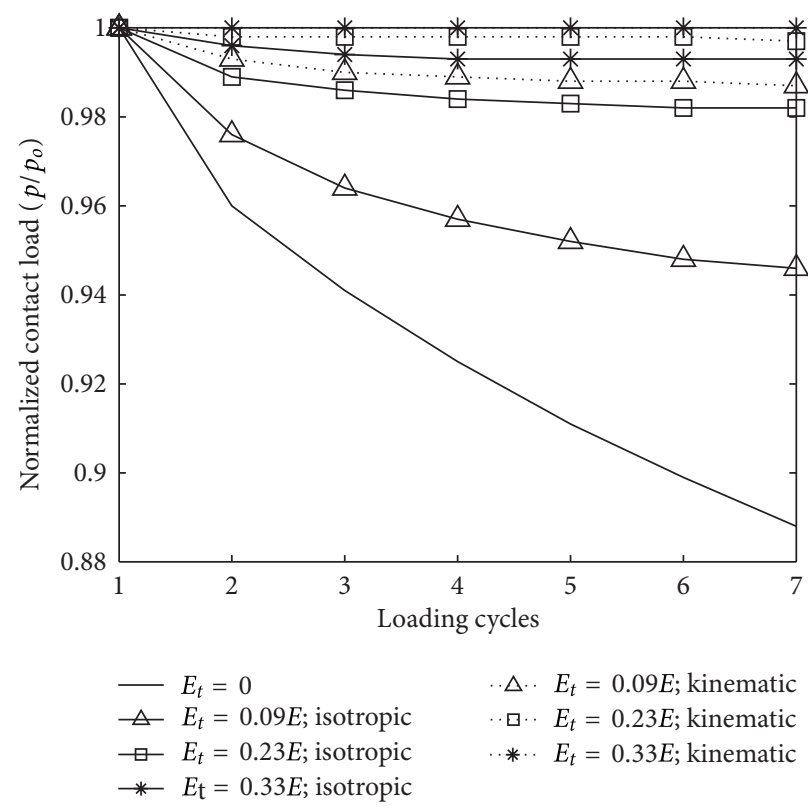

(b)

Figure 12: Normalized contact load, $P / P_{0}$, as a function of loading cycles for maximum loading, (a) $\omega_{\max }^{*}=100$, (b) $\omega_{\max }^{*}=200$.

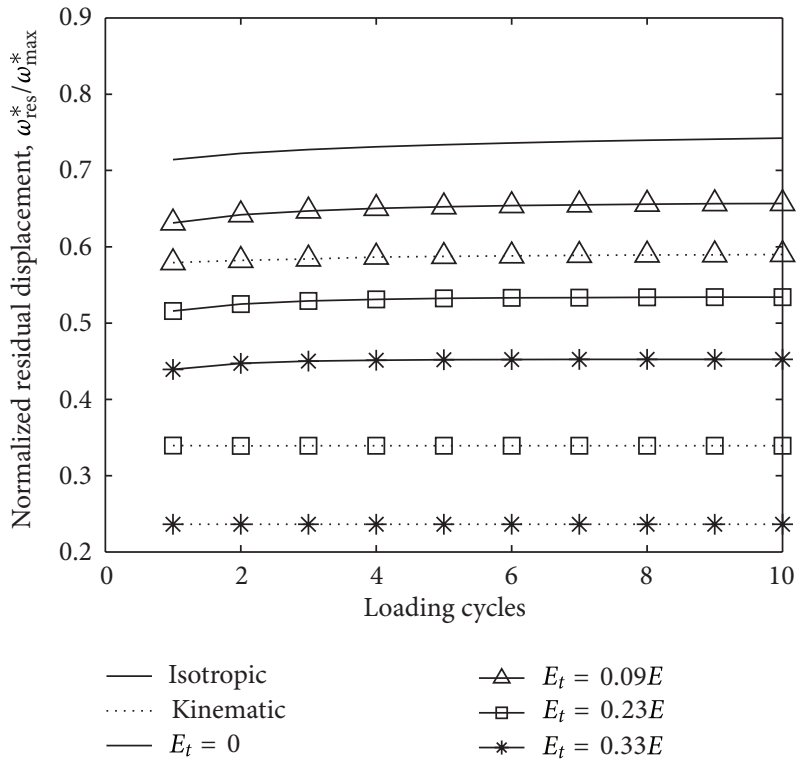

(a)

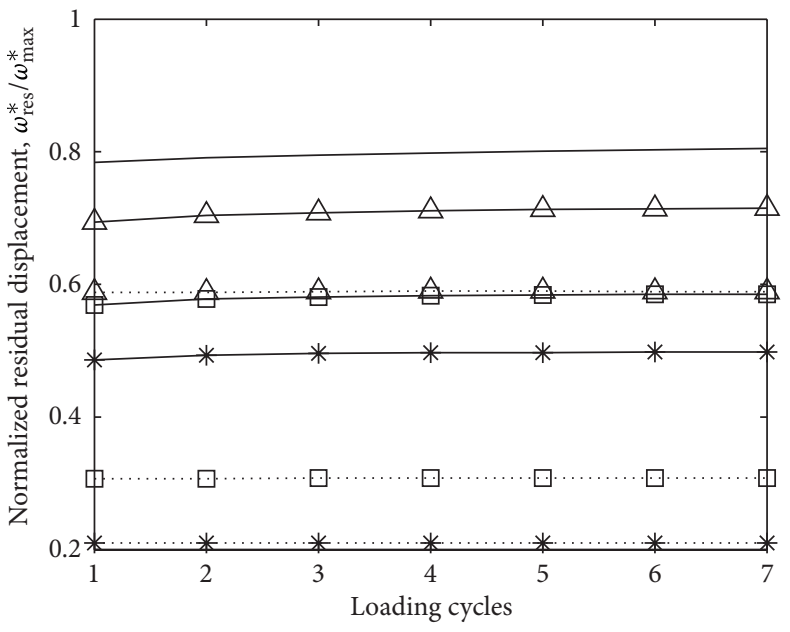

$\begin{array}{ll}- \text { Isotropic hardening } & \triangle E_{t}=0.09 E \\ \ldots . . . \quad \text { Kinematic hardening } & \square-E_{t}=0.23 E \\ -E_{t}=0 & \rightarrow-E_{t}=0.33 E\end{array}$

(b)

FIGURE 13: Normalized residual interference, $\omega_{\text {res }}^{*} / \omega_{\max }^{*}$, as a function of loading cycles for maximum loading, (a) $\omega_{\max }^{*}=100$, (b) $\omega_{\max }^{*}=200$.

of residual interference with increasing loading unloading cycles. This may cause early shakedown at higher maximum dimensionless interference of loading.

4.2.4. Contact Area with Loading Cycles. Figure 15(a) presents the normalized contact area at the end of each loading. $A_{0}$ is the contact area at the end of first loading. The present simulation consists ten loading unloading cycles. Two different maximum dimensionless loadings $\left(P^{*}=48\right.$ and 116) are used in this simulation and the results are compared with the available literature. Ovcharenko et al. [28] found in their experiments an increase of around 5.3\% and $8 \%$ of $A / A_{0}$ with elastic perfectly plastic copper sphere $(E / Y=400)$ using maximum dimensionless loading $\left(P^{*}\right)$ of 48 and 116 at the end of tenth loading. Zait et al. [24] estimated $8-9 \%$ growth of $A / A_{0}$ after sixth loading with the deformable sphere $(E / Y=1000)$ against a rigid flat using maximum dimensionless loading $\left(P^{*}\right)$ of 40 . We have used deformable sphere of $\mathrm{E} / \mathrm{Y}$ ratio 700 , our simulation resulted 


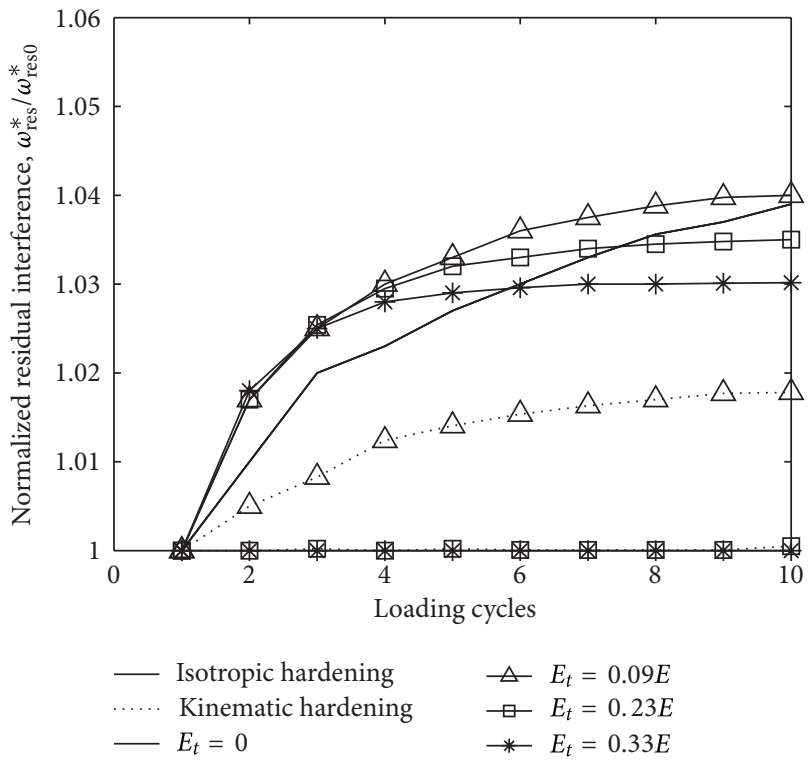

(a)

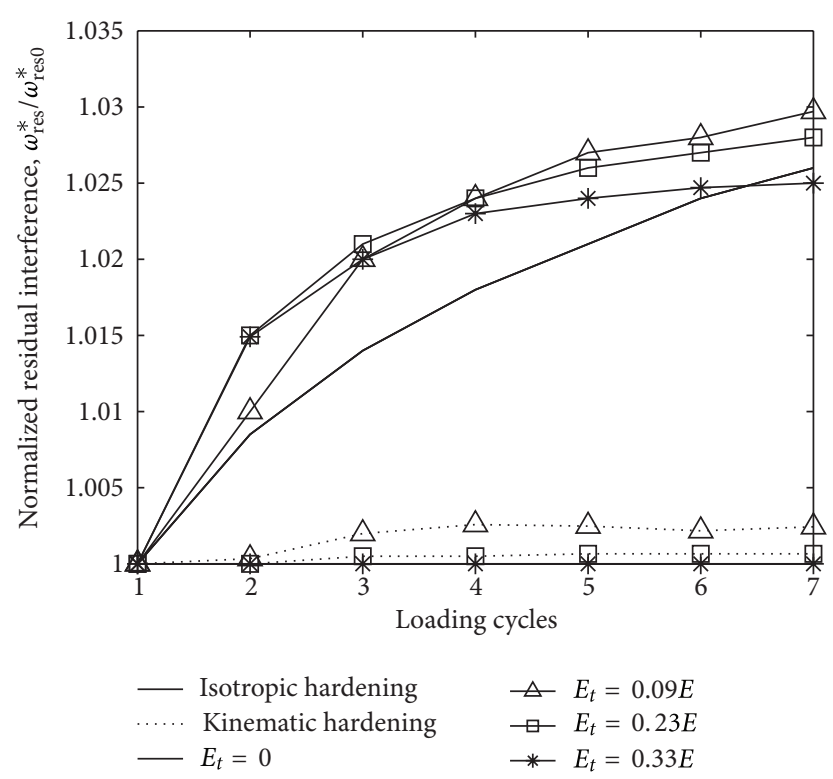

(b)

FIGURE 14: Normalized residual interference, $\omega_{\text {res }}^{*} / \omega_{\text {res } 0}^{*}$, as a function of loading cycles for maximum loading, (a) $\omega_{\max }^{*}=100$, (b) $\omega_{\max }^{*}=200$.

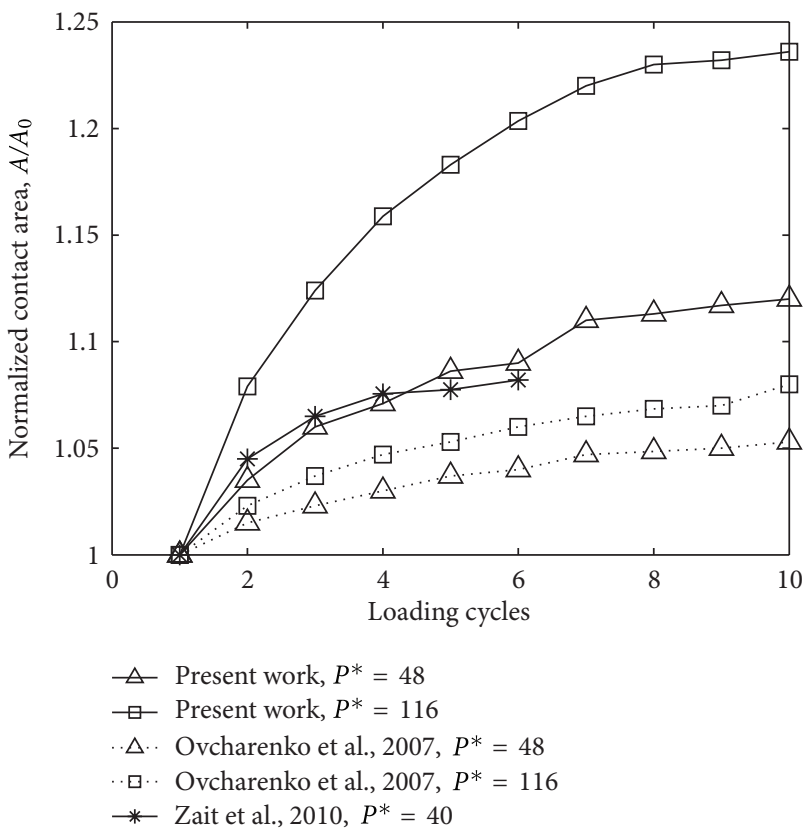

(a)

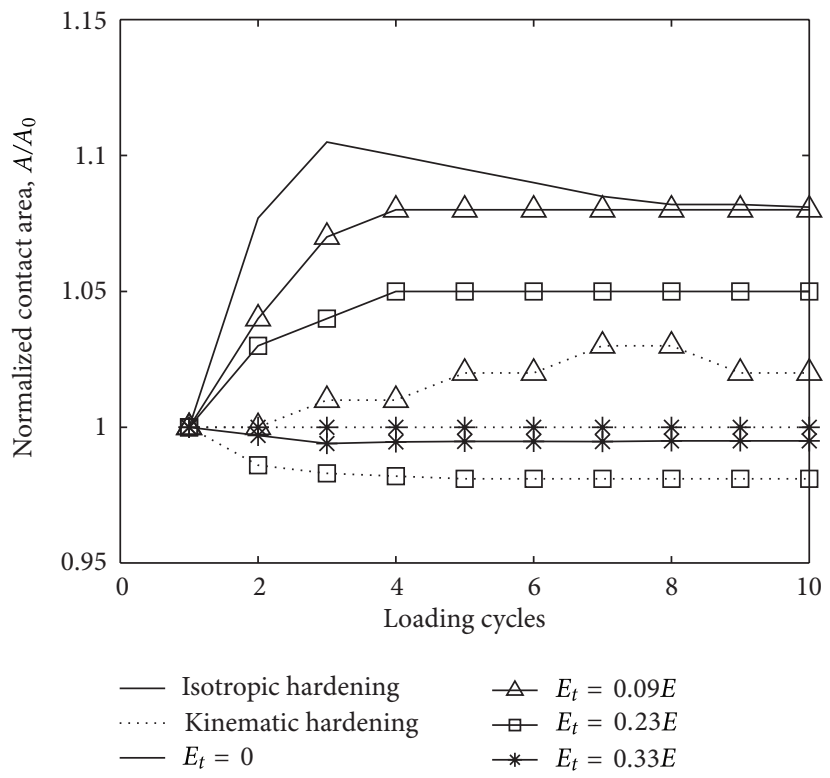

(b)

FiguRE 15: Normalized contact area, $A / A_{0}$, as a function of the number of loading cycles; (a) comparison of different studies; (b) comparison of hardening models for maximum loading, $\omega_{\max }^{*}=100$.

$12 \%$ and $23.5 \%$ increase of $A / A_{0}$ for the maximum loading $\left(P^{*}\right)$ of 48 and 116 , respectively, after tenth loading. The agreement between the present results and the findings of Zait et al. [24] is appreciably good. The variation of our results with that of Ovcharenko et al. [28] is due to the fact they have used elastic flat contrary to our assumption of rigid flat. Moreover the variation can be attributed to some extent to the discrete meshing of contact elements with finite resolution and the magnitude of the contact element stiffness used in the finite element software during evaluating contact radius. It is also evident from the figure that the growth of normalized contact area increases with the increase of maximum loading.

Figure 15(b) shows the growth of normalized contact area after each loading cycle with four different tangent modules 
using isotropic and kinematic hardening. It is evident from the plot that the contact area increases slightly after each loading cycles indicating marginal effect of strain hardening in isotropic hardening. The materials with kinematic hardening exhibit very less increase of contact area during ten loading cycles with maximum dimensionless interference of loading $\omega^{*}=100$. Small discrepancy was observed for the results of higher tangent modulus $\left(E_{t}=0.23 E\right.$ and $\left.0.33 E\right)$ in kinematic hardening, probably due to the discretization of contact elements as discussed earlier.

\section{Conclusion}

The effect of strain hardening and hardening models on the contact parameters during the multiple normal loading unloading under full stick contact were analyzed with finite element software ANSYS. The sphere was deformed against a rigid flat with the maximum interference up to 200 times the interference necessary for initial yield. Maximum ten repeated loading unloading cycles were performed with different plastic properties using isotropic and kinematic hardening models. The contact load decreases and the residual interference increases with the increase in loading unloading cycles. The variations of contact parameters with the increase in loading unloading cycles are predominantly due to the contact conditions. Under full stick contact condition, the effect of hardening model on the variation of contact parameters is more pronounced at large tangent modulus. Thus small variation of tangent modulus resulted same shakedown behavior and similar interfacial parameters in repeated loading unloading with both the hardening rule as reported in literature. However at high tangent modulus, the strain hardening and hardening rules have strong influences on contact parameters like mean contact pressure, contact load, residual interference and contact area.

It was found that the evolution of mean contact pressure depends predominantly on the strain hardening characteristics and the intensity of loading. The mean contact pressure increases with the increase in tangent modulus and intensity of loading. However the variation of mean contact pressure owing to the change of hardening model is not significant even at large load. The mean contact pressure decreases with the increase in loading cycles in isotropic hardening. This decrease is prominent after second loading although due to the increased interfacial conformity, the decrease is not so pronounced in subsequent cycles. Kinematic hardening produced insignificant variation of mean contact pressure with increasing loading cycles. The contact load decreases with the increase in loading cycles. The rate of decrease increases with tangent modulus and the intensity of maximum loading. The decrease of contact load is large enough in isotropic hardening for the materials with low tangent modulus compared to kinematic hardening for the materials with high tangent modulus.

The residual interference varies with both tangent modulus and hardening model. The residual interference decreases with the increase in tangent modulus and it is significantly higher in isotropic hardening compared to that with kinematic hardening. The increase in residual interference with the increasing number of unloading cycles was severely affected by hardening model at high tangent modulus. The contact area increases slightly after each loading cycles in isotropic hardening whereas the materials with kinematic hardening exhibit very less increase of contact area. The growth of contact area was found to be independent of strain hardening but increases with the increase in intensity of loading. The effect of hardening model on contact parameters at high tangent modulus clearly indicates different shakedown behavior for isotropic and kinematic hardening for repeated normal loading unloading under full stick contact condition. The analysis of hysteretic loops at high tangent modulus is an interesting field for future study.

\section{Nomenclature}

a: Contact area radius

E: Modulus of elasticity of the sphere

$Y$ : Yield Strength of the sphere material

A: Real contact area

$R:$ Radius of the sphere

$P$ : Contact load

$\omega$ : Interference

$v$ : Poisson's ratio of sphere

$p$ : Mean contact pressure

$E_{t}$ : Tangent modulus of the sphere

$P^{*}$ : Dimensionless contact load, $P / P_{c}$, in stick contact

$A^{*}$ : Dimensionless contact area, $A / A_{c}$, in stick contact

$\omega^{*}$ : Dimensionless interference, $\omega / \omega_{c}$, in stick contact.

\section{Subscripts}

c: $\quad$ Critical values

res: Residual values following unloading

max: Maximum values during loading-unloading process.

Superscripts

* : Dimensionless.

\section{References}

[1] S. Majumder, N. E. McGruer, G. G. Adams et al., "Study of contacts in an electrostatically actuated microswitch," Sensors and Actuators A, vol. 93, no. 1, pp. 19-26, 2001.

[2] S. Majumder, N. E. McGruer, and G. G. Adams, "Contact resistance and adhesion in a MEMS microswitch," in Proceedings of STLE/ASME Joint International Tribology Conference, TRIB270, pp. 1-6, 2003.

[3] W. Peng and B. Bhushan, "Transient analysis of sliding contact of layered elastic/plastic solids with rough surfaces," Microsystem Technologies, vol. 9, no. 5, pp. 340-345, 2003.

[4] J. Y. Kim, A. Baltazar, and S. I. Rokhlin, "Ultrasonic assessment of rough surface contact between solids from elastoplastic loading-unloading hysteresis cycle," Journal of the Mechanics and Physics of Solids, vol. 52, no. 8, pp. 1911-1934, 2004. 
[5] A. Kapoor, F. J. Franklin, S. K. Wong, and M. Ishida, "Surface roughness and plastic flow in rail wheel contact," Wear, vol. 253, no. 1-2, pp. 257-264, 2002.

[6] J. A. Williams, I. N. Dyson, and A. Kapoor, "Repeated loading, residual stresses, shakedown, and tribology," Journal of Materials Research, vol. 14, no. 4, pp. 1548-1559, 1999.

[7] H. Hertz, "Über die Berührung fester elastischer Köper," Journal für die reine und angewandte Mathematik, vol. 92, pp. 156-171, 1882.

[8] J. E. Merwin and K. L. Johnson, "An analysis of plastic deformation in rolling contact," Proceedings of Institution of Mechanical Engineers, vol. 177, pp. 676-685, 1963.

[9] S. M. Kulkarni, G. T. Hahn, C. A. Rubin, and V. Bhargava, "Elastoplastic finite element analysis of three-dimensional, pure rolling contact at the shakedown limit," Journal of Applied Mechanics, Transactions ASME, vol. 57, no. 1, pp. 57-64, 1990.

[10] V. Bhargava, G. T. Hahn, and C. A. Rubin, "An elastic-plastic finite element model of rolling contact Part 1: analysis of single contacts," Journal of Applied Mechanics, Transactions ASME, vol. 52, no. 1, pp. 67-74, 1985.

[11] V. Bhargava, G. T. Hahn, and C. A. Rubin, "An elastic-plastic finite element model of rolling contact Part 2: analysis of repeated contacts," Journal of Applied Mechanics, Transactions ASME, vol. 52, no. 1, pp. 75-82, 1985.

[12] P. Sahoo, D. Adhikary, and K. Saha, "Finite element based elastic-plastic contact of fractal surfaces considering strain hardening," Journal of Tribology and Surface Engineering, vol. 1, pp. 39-56, 2010.

[13] L. Kogut and I. Etsion, "Elastic-plastic contact analysis of a sphere and a rigid flat," Journal of Applied Mechanics, Transactions ASME, vol. 69, no. 5, pp. 657-662, 2002.

[14] I. Etsion, Y. Kligerman, and Y. Kadin, "Unloading of an elasticplastic loaded spherical contact," International Journal of Solids and Structures, vol. 42, no. 13, pp. 3716-3729, 2005.

[15] R. Jackson, I. Chusoipin, and I. Green, "A finite element study of the residual stress and deformation in hemispherical contacts," Journal of Tribology, vol. 127, no. 3, pp. 484-493, 2005.

[16] Y. Kadin, Y. Kligerman, and I. Etsion, "Multiple loadingunloading of an elastic-plastic spherical contact," International Journal of Solids and Structures, vol. 43, no. 22-23, pp. 7119-7127, 2006.

[17] E. R. Kral, K. Komvopoulos, and D. B. Bogy, "Elastic-plastic finite element analysis of repeated indentation of a half-space by a rigid sphere," Journal of Applied Mechanics, Transactions ASME, vol. 60, no. 4, pp. 829-841, 1993.

[18] P. . Sahoo, B. Chatterjee, and D. Adhikary, "Finite element based Elastic-plastic contact behavior of a sphere against a rigid flatEffect of Strain Hardening," International Journal of Engineering and Technology, vol. 2, no. 1, pp. 1-6, 2010.

[19] B. Chatterjee and P. Sahoo, "Effect of strain hardening on unloading of a deformable sphere loaded against a rigid flata finite element study," International Journal of Engineering and Technology, vol. 2, no. 4, pp. 225-233, 2010.

[20] P. Sahoo, Engineering Tribology, PHI Learning Private Limited, New Delhi, India, 2009.

[21] V. Brizmer, Y. Kligerman, and I. Etsion, "The effect of contact conditions and material properties on the elasticity terminus of a spherical contact," International Journal of Solids and Structures, vol. 43, no. 18-19, pp. 5736-5749, 2006.

[22] B. Chatterjee and P. Sahoo, "Elastic-plastic contact of a deformable sphere against a rigid flat for varying material properties under full stick contact condition," Tribology in Industry, vol. 33, no. 4, pp. 164-172, 2011.

[23] Y. Zait, Y. Kligerman, and I. Etsion, "Unloading of an elasticplastic spherical contact under stick contact condition," International Journal of Solids and Structures, vol. 47, no. 7-8, pp. 990-997, 2010.

[24] Y. Zait, V. Zolotarevsky, Y. Kligerman, and I. Etsion, "Multiple normal loading-unloading cycles of a spherical contact under stick contact condition," Journal of Tribology, vol. 132, no. 4, Article ID 041401, 7 pages, 2010.

[25] B. Chatterjee and P. Sahoo, "Effect of strain hardening on elasticplastic contact of a deformable sphere against a rigid flat under full contact condition," Advances in Tribology, vol. 2012, Article ID 472794, 8 pages, 2012.

[26] K. L. Johnson, Contact Mechanics, Cambridge University Press, Cambridge, Mass, USA, 1985.

[27] S. Shankar and M. M. Mayuram, "Effect of strain hardening in elastic-plastic transition behavior in a hemisphere in contact with a rigid flat," International Journal of Solids and Structures, vol. 45, no. 10, pp. 3009-3020, 2008.

[28] A. Ovcharenko, G. Halperin, G. Verberne, and I. Etsion, "In situ investigation of the contact area in elastic-plastic spherical contact during loading-unloading," Tribology Letters, vol. 25, no. 2, pp. 153-160, 2007.

[29] V. Zolotarevskiy, Y. Kligerman, and I. Etsion, "Elastic-plastic spherical contact under cyclic tangential loading in pre-sliding," Wear, vol. 270, no. 11-12, pp. 888-894, 2011.

[30] F. Wang and L. M. Keer, "Numerical simulation for three dimensional elastic-plastic contact with hardening behavior," Journal of Tribology, vol. 127, no. 3, pp. 494-502, 2005. 

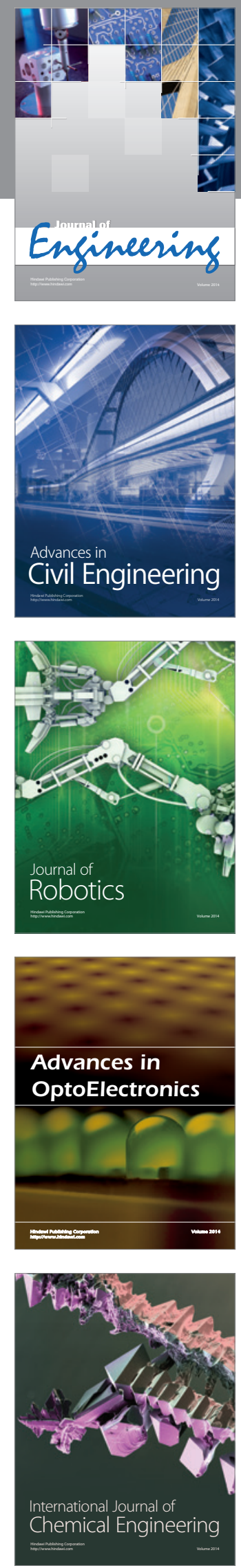

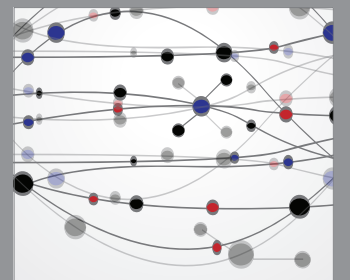

The Scientific World Journal
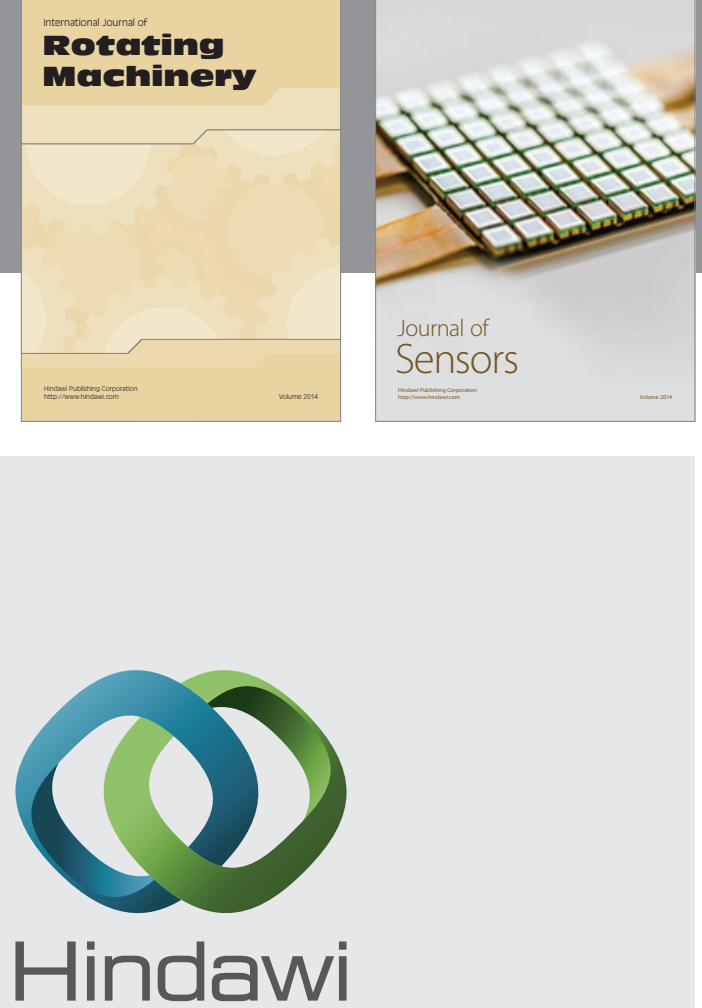

Submit your manuscripts at http://www.hindawi.com
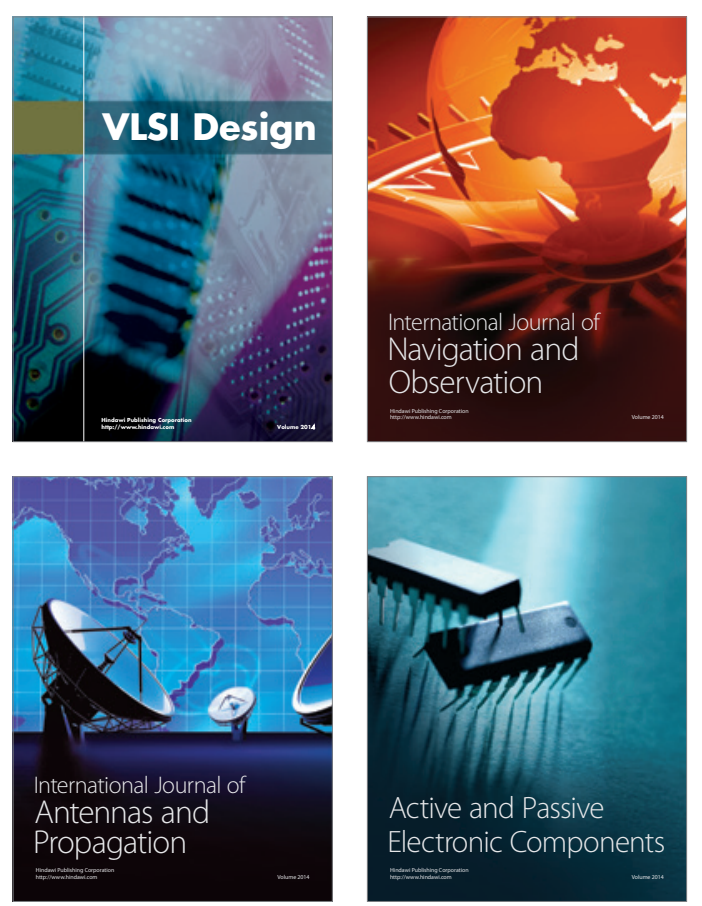
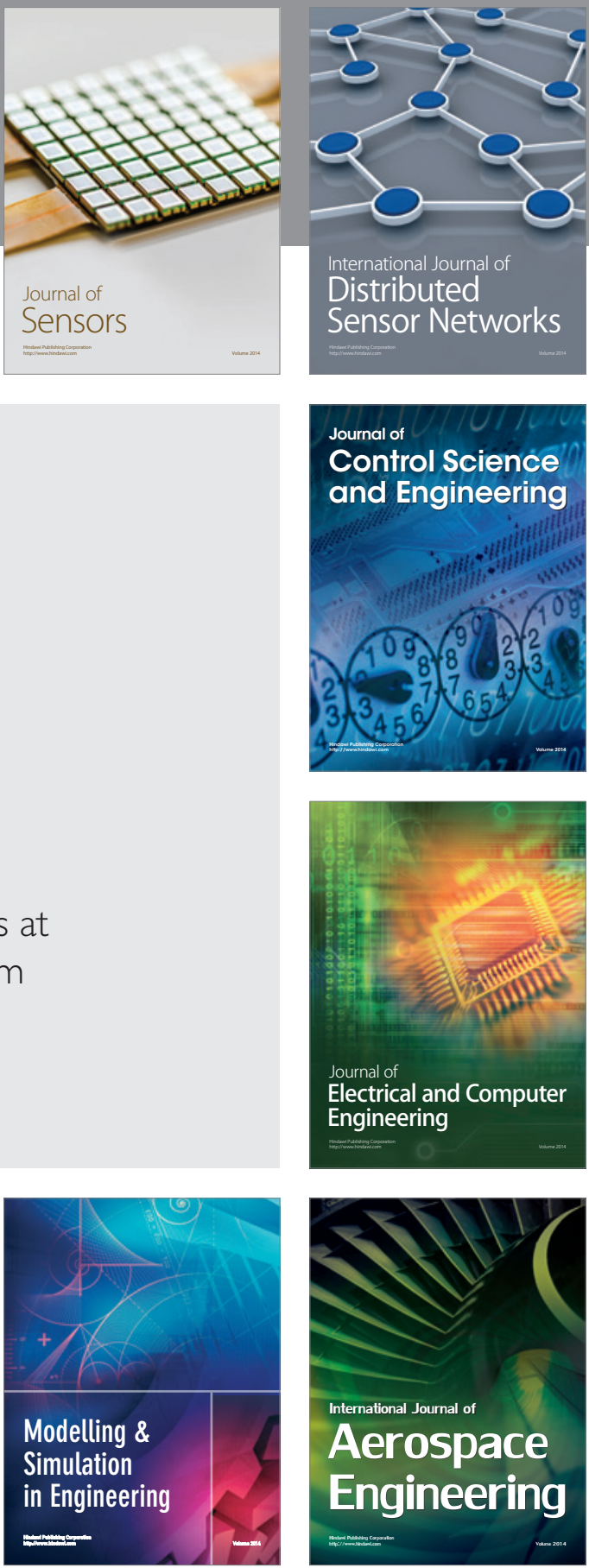

Journal of

Control Science

and Engineering
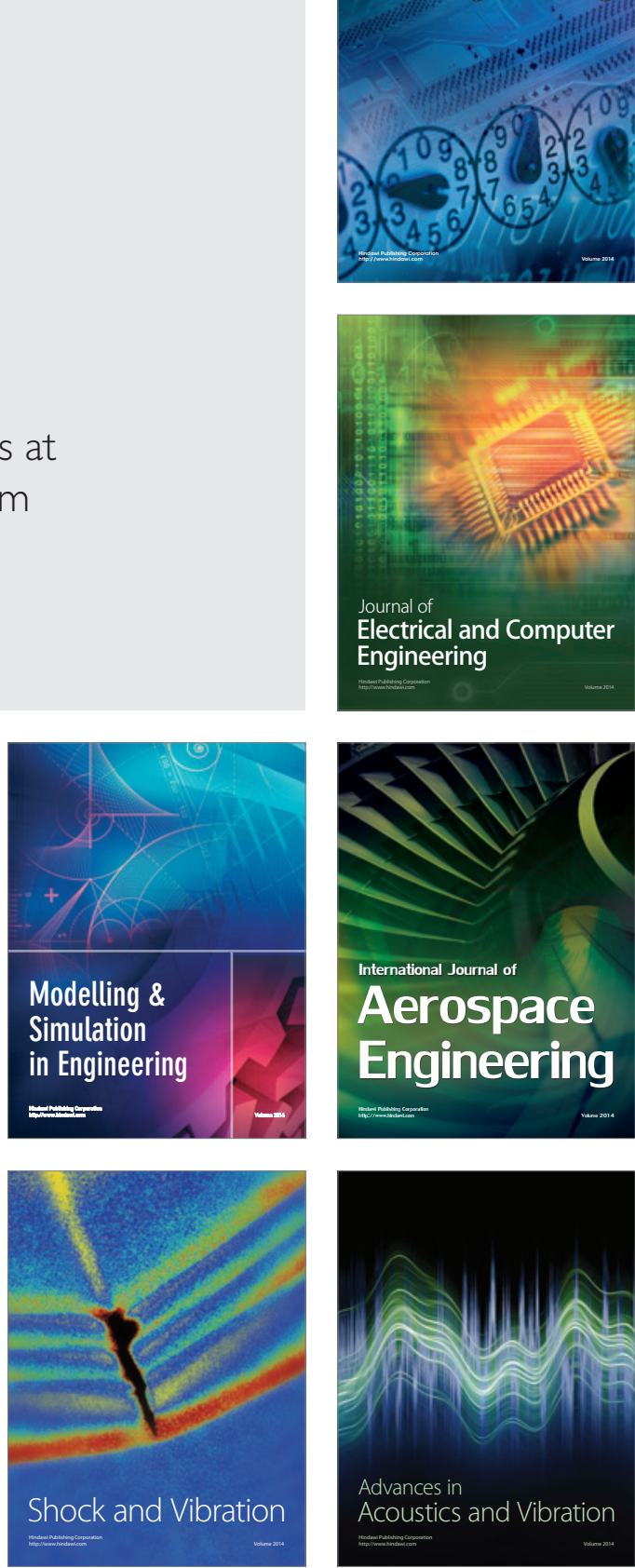